\title{
Antimicrobial Peptides Pom-1 and Pom-2 from Pomacea poeyana Are Active against Candida auris, C. parapsilosis and C. albicans Biofilms
}

\author{
Heinz Fabian Raber ${ }^{1,+}$, Jetmira Sejfijaj ${ }^{1,+}{ }^{+}$, Ann-Kathrin Kissmann ${ }^{1}$, Andreas Wittgens ${ }^{1}$, \\ Melaine Gonzalez-Garcia ${ }^{2}$, Annia Alba ${ }^{3}{ }^{(}$, Antonio A. Vázquez ${ }^{3}$, Fidel E. Morales Vicente ${ }^{4,5}$, \\ Julio Pérez Erviti ${ }^{2}$ D, Dennis Kubiczek ${ }^{1}$, Anselmo Otero-González ${ }^{2}$, Armando Rodríguez ${ }^{6}{ }^{\mathbb{D}}$, \\ Ludger Ständker 6 (D) and Frank Rosenau $1,7, * \mathbb{D}$
}

Citation: Raber, H.F.; Sejfijaj, J. Kissmann, A.-K.; Wittgens, A.; Gonzalez-Garcia, M.; Alba, A.; Vázquez, A.A.; Morales Vicente, F.E.; Erviti, J.P.; Kubiczek, D.; et al Antimicrobial Peptides Pom-1 and Pom-2 from Pomacea poeyana Are Active against Candida auris, $C$. parapsilosis and C. albicans Biofilms. Pathogens 2021, 10, 496. https:// doi.org/10.3390/pathogens10040496

Academic Editor: Saad Taj-Aldeen

Received: 25 March 2021

Accepted: 17 April 2021

Published: 20 April 2021

Publisher's Note: MDPI stays neutral with regard to jurisdictional claims in published maps and institutional affiliations.

Copyright: (c) 2021 by the authors. Licensee MDPI, Basel, Switzerland. This article is an open access article distributed under the terms and conditions of the Creative Commons Attribution (CC BY) license (https:// creativecommons.org/licenses/by/ $4.0 /)$
1 Institute of Pharmaceutical Biotechnology, Ulm University, 89081 Ulm, Germany; Heinz.Raber@uni-ulm.de (H.F.R.); jetmira.sejfijaj@uni-ulm.de (J.S.); ann-kathrin.kissmann@uni-ulm.de (A.-K.K.); a.wittgens@gmx.de (A.W.); dennis.kubiczek@gmx.com (D.K.)

2 Center for Protein Studies, Faculty of Biology, University of Havana, 25 Street, Havana 10400, Cuba; mgonzalez@fbio.uh.cu (M.G.-G.); julio.perez@fbio.uh.cu (J.P.E.); aotero@fbio.uh.cu (A.O.-G.)

3 Pedro Kourí Institute for Tropical Medicine, Havana 13600, Cuba; annia.alba@gmail.com (A.A.); antonivp@ipk.sld.cu (A.A.V.)

4 General Chemistry Department, Faculty of Chemistry, University of Havana, Zapata y G, Havana 10400, Cuba; femvicente@gmail.com

5 Synthetic Peptides Group, Center for Genetic Engineering and Biotechnology, P.O. Box 6162, Havana 10600, Cuba

6 Core Facility for Functional Peptidomics, Faculty of Medicine, Ulm University, 89081 Ulm, Germany; armando.rodriguez-alfonso@uni-ulm.de (A.R.); ludger.staendker@uni-ulm.de (L.S.)

7 Max Planck Institute for Polymer Research Mainz, Ackermannweg 10, 55128 Mainz, Germany

* Correspondence: frank.rosenau@uni-ulm.de

+ Authors contributed equally.

Abstract: Recently two peptides isolated from the Cuban freshwater snail Pomacea poeyana (Pilsbry, 1927) were described to have antimicrobial activity against bacterial pathogens. Here we show considerable activities of Pom- 1 and Pom-2 to reduce the viability of C. albicans, C. parapsilosis and the less common species $C$. auris measured as the decrease of metabolic activity in the resazurin reduction assay for planktonic cells. Although these activities were low, Pom-1 and Pom-2 turned out to be highly potent inhibitors of biofilm formation for the three Candida species tested. Whereas Pom-1 was slightly more active against $C$. albicans and C. parapsilosis as representatives of the more common Candida species Pom-2 showed no preference and was fully active also against biofilms of the more uncommon species $C$. auris. Pom- 1 and Pom- 2 may represent promising lead structures for the development of a classical peptide optimization strategy with the realistic aim to further increase antibiofilm properties and other pharmacologic parameters and to generate finally the first antifungal drug with a pronounced dedication against Candida biofilms.

Keywords: antimicrobial peptide; Candida species; biofilm

\section{Introduction}

Although generations of microbiologists regarded the traditional microbiological cultivation in Erlenmeyer-flasks as the most preferable condition for their research organisms, biofilms formed on different materials as substrates are by far the most relevant and the "normal" lifestyle for microorganisms in general [1]. This is in principle also the case for all relevant pathogenic bacteria and lower eukaryotes. Estimations exists that biofilms may be associated with $65 \%$ of hospital acquired infections and may account for more than $80 \%$ of all microbial infections [2-4]. Almost undisputed is a key feature of microbial biofilms which has been recognized as a significant increase of resistance to chemical and physical 
stresses, qualifying them as a major thread in clinical environments and their treatment as a socio-economical challenge for health systems [5,6]. Fungi of the genus Candida represent a class of highly important pathogens with the commensal yeast $C$. albicans probably being the most abundant and common species in clinical fungal infections [7]. In their life a majority of women of $75 \%$ will suffer from Candidiasis and $85-95 \%$ of these infections in this group of patients are caused by C. albicans [8]. However the leading role of C. albicans in invasive infections is decreasing in the last decades and other Candida species increase in accounting for infections [9-11]. Among them Candida parapsilosis is relevant, as it is able to form persistent biofilms on catheters, medically implanted devices and all abiotic or biotic surfaces in medical care units, thus posing severe threads to the patients especially after invasive surgery. In addition, C. parapsilosis is perfectly nourished by total parenteral nutrition of patients, thereby representing a more then considerable risk for undernourished children and low-birth-weight neonates [9,11-14]. Furthermore, several clinical isolates of this species have been reported to lose susceptibility to important classes of antifungal drugs, which poses severe limitations to efficient treatment regimes [15-18].

Candida auris, however, is a more recently discovered pathogenic yeast and thus probably one of the most uncommon Candida which was first isolated in 2009 from a Japanese patient [19]. C. auris can cause severe bloodstream infections in hospitalized patients and can lead to remarkably high mortalities between $35 \%$ and $60 \%$ [20,21]. Special threat arises from the fact that strains of $C$. auris with multiple drug-resistances (probably by upregulation of ABC-type efflux pumps [22]) against prominent antifungal drugs have occurred independently in different countries/continents worldwide [23]. Thus, both, the U.S. center for disease control (CDC) and the European center for disease control (ECDC) have released clinical alerts, initiating also a broad public discourse, identifying $C$. auris as an emerging "superbug" [24]. Multi-drug resistance of C. auris against classical antifungal drugs like fluconazole or amphotericin $B$ has been discussed to be caused by the activity of ABC-type MFS (major facilitator superfamily) efflux pumps [22], which are even overexpressed in C. auris when living in biofilms [25]. Based on these reports, biofilm formation and the resulting increase of physiological robustness can be regarded as a key feature of virulence by common, as well as by uncommon Candida species to successfully establish their full pathogenic potential in combination with resistance against classical fungicides. Currently, no biofilm-specific drugs exist today for Candida species or any other microbe, making treatment of biofilm-based infections particularly problematic [26]. In our opinion, systematic studies to isolate specific anti-biofilm drug molecules against Candida species are currently far from being common in the scientific community but they are urgently needed. They could represent the scientific foundation for the development of a completely new piece of munition in the fight against pathogenic microbes in general based on the novel activities against their biofilms. Simplified to the extreme the formation of elaborate microbial biofilms can be divided into only four phases, the attachment of planktonic cells to the future biofilm substratum, the assembly of cells and the subsequent growth into microcolony like structures, the development of species-specific mature architectures of the biofilm and finally the release of the previous biofilm cells into the planktonic phase (Figure 1). 


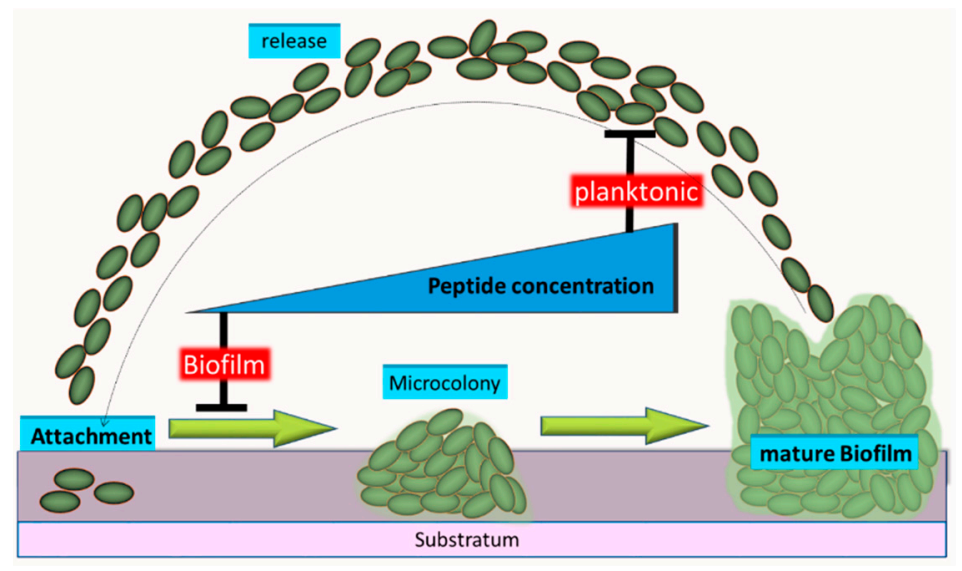

Figure 1. Schematic overview of a typical Candida biofilm and stages of action for Pom-1 and Pom-2 on biofilm development. The simplified biofilm formation process can be divided into four phases, (i) the attachment of planktonic cells to the future biofilm substratum, (ii) the aggregation of cells and their subsequent growth into microcolony like structures and (iii) the development of species-specific mature biofilm architectures. (iv) Release of cells into the planktonic phase delivers Candida seeds for the next generation of biofilms. Already low concentrations of Pom- 1 and Pom- 2 can inhibit the development of biofilms, whereas only unreasonably high concentration of the peptide is required to affect the viability of planktonic cells.

One promising class of new therapeutic molecules not only in the fight against planktonic Candida cells but also against biofilms of these pathogenic yeasts are antimicrobial peptides (AMPs). Most AMPs have a simple physical mode of action reducing the functional integrity of microbial cell membranes. They act probably by forming "barrel stave" like [27-29], "toroidal" like [29-31] or "carpet" like [29] pores or related activities [32,33] and can be considered to provide excellent treatment options even against organisms resistant to conventional antifungal drugs. The AMP Cm-p5 derived from a natural peptide originally isolated from the coastal mollusk Cenchritis muricatus exhibited efficient antifungal activity against different fungal pathogens [34] including C. auris [35,36], with only neglectable cytotoxic effects towards mammalian cells [34]. Interestingly, synthetic dimeric derivatives of Cmp-5 exhibited a considerable activity towards $C$. auris biofilms on an abiotic substratum inhibiting the growth of biofilms but had only low activities against the respective planktonic cells compared to the original Cm-p5 [37]. Recently we have described another set of AMPs isolated from the Cuban freshwater snail Pomacea poeyana (Pilsbry, 1927) [38]. These two peptides named Pom-1 and Pom-2 demonstrated high antimicrobial activity against the Gram-negative bacteria such as Pseudomonas aeruginosa while it demonstrates only a moderate activity against Klebsiella pneumoniae and Listeria monocytogenes in combination with low toxicity towards primary human macrophages [38].

Here we show considerable activities of Pom-1 and Pom-2 to reduce the viability of C. albicans, C. parapsilosis and the less common species C. auris measured as the decrease of metabolic activity in the resazurin reduction assay for planktonic cells [39]. Although these activities can only be considered to be at least limited Pom-1 and Pom-2 turned out to be highly potent inhibitors of biofilm formation for the three Candida species tested. Whereas Pom-1 was slightly more active as compared to Pom-2 against C. albicans and C. parapsilosis as representatives of the more common Candida species Pom-2 showed no preference and was fully active also against the uncommon species C. auris. Pom- 1 and Pom-2 may represent promising lead structures for the development of a classical peptide optimization strategy with a realistic aim to further increase antibiofilm properties and other pharmacologic parameters and to isolate finally the first antifungal drug with a pronounced dedication against Candida biofilms. 


\section{Results and Discussion}

Pom-1 is a 34 amino acid peptide comprising a predicted structure of two alpha helices connected by a 6 aa loop (Figure 2a), whereas Pom-2 has a sequence length of 33 aa also delivering a predicted secondary structure of two alpha helices joint in this case by only three amino acids (Figure 2b).

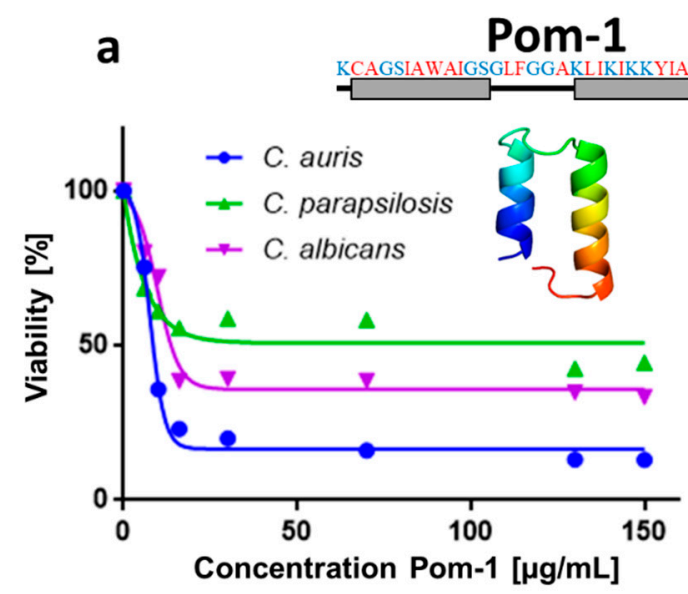

b

Pom-2
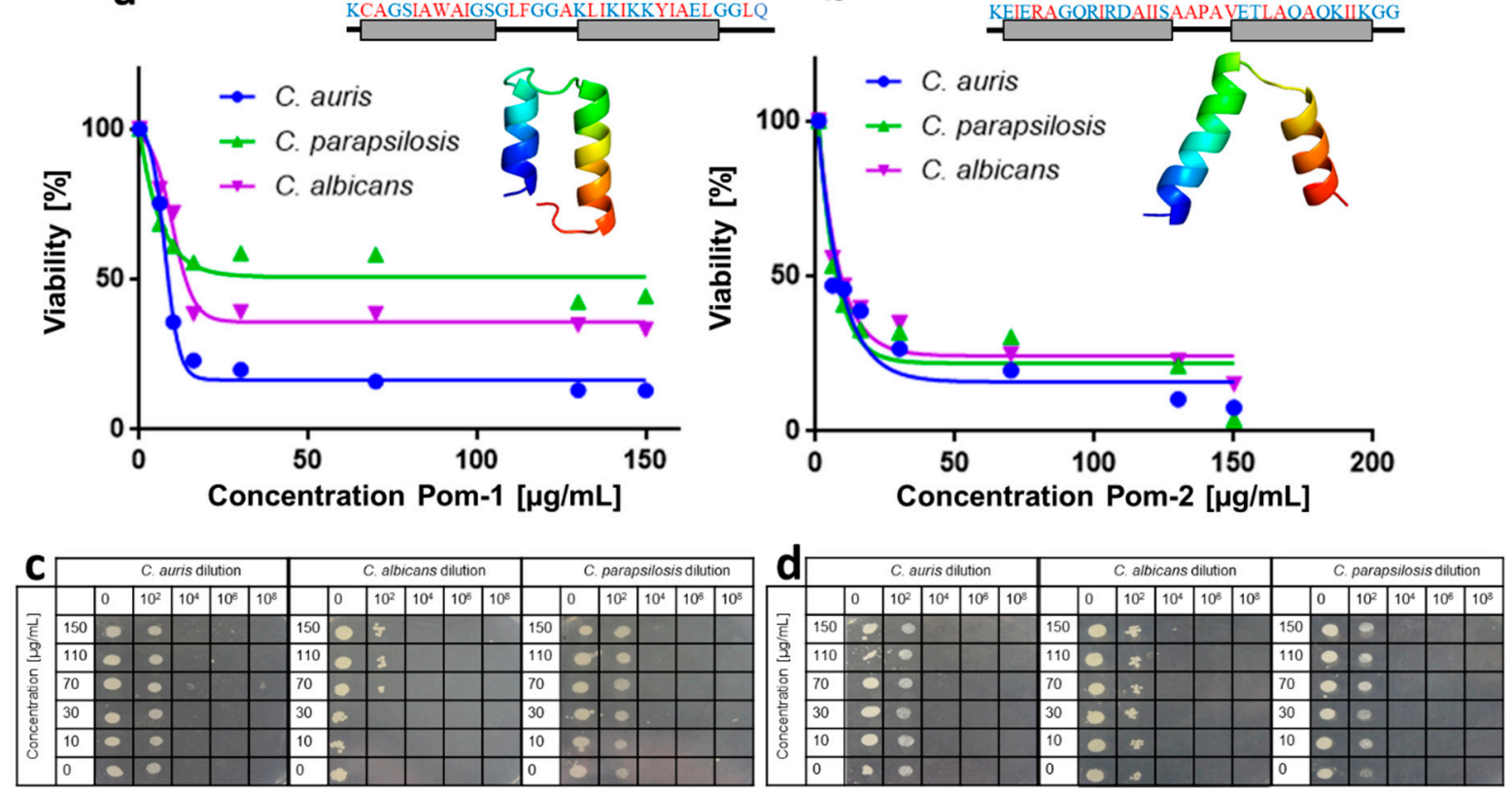

Figure 2. Action of Pom-1 and Pom-2 on the Candida species. (a,b) Pom-1 and Pom-2 dose-dependent activity of Candida species viability determined by the resazurin reduction test. All experiments were performed in triplicates. Standard deviations have been calculated and found to be too low to be visible in the graphs. Modelled 3D-structure of Pom-1 and Pom-2 using the QUARK and SwissModel server and the corresponding amino acid sequence [38]. The red letters represent hydrophobic amino acids and the blue hydrophilic. Grey boxes represent alpha-helix structures. (c,d) plate-spot assay for Pom-1 and Pom-2 measuring antifungal activities against dilutions of C. auris, C. albicans and C. parapsilosis. Colony formation was monitored after $24 \mathrm{~h}$ of growth in the presence of increasing concentrations in $10^{2}, 10^{4}, 10^{6}$ and $10^{8}$ dilutions of the original cultures, which were adjusted to identical optical densities prior peptide addition. Dilutions were then spotted on agar plates and further incubated for another $24 \mathrm{~h}$ at $37^{\circ} \mathrm{C}$.

\subsection{Activity against Planktonic Cells}

Antifungal testing was done in this study by an assay combining the classical susceptibility test according to the Clinical and Laboratory Standards Institute (NCCLS) M27-A2 approved standard protocol as a reference method for broth dilution antifungal susceptibility testing of yeast [40] with rapid resazurin based measurements of cell viability for assessing the toxicity of fungicides [39] thereby replacing the simple optical inspection and ranking of turbidity by the more sensitive fluorescence measurement of resorufin in the latter assay. In this assay performed with planktonic cells of the respective yeasts the peptide Pom-1 delivered semi-inhibitory concentrations for planktonic cell viability (IC50P) values of $8.5 \mu \mathrm{g} / \mathrm{mL}$ for C. auris $13.8 \mu \mathrm{g} / \mathrm{mL}$ for C. albicans and $36.9 \mu \mathrm{g} / \mathrm{mL}$ for C. parapsilosis with a generally only moderate activity but with a slight preference for C. auris (Figure 2a,c). With $\mathrm{IC}_{50 \mathrm{P}}$ values of $8.4 \mu \mathrm{g} / \mathrm{mL}$ for C. auris $9.3 \mu \mathrm{g} / \mathrm{mL}$ for C. albicans and $7.5 \mu \mathrm{g} / \mathrm{mL}$ for C. parapsilosis the overall activity of Pom-2 was comparable but with almost identical courses of the curves (Figure $2 b, d$ ). Although the $\mathrm{IC}_{50 \mathrm{P}}$ values appeared to suggest promising activities for both peptides, the inhibition was incomplete with viabilities approximating $13 \%$ for Pom- 1 and $8 \%$ for Pom- 2 for C. auris as the most susceptible species in our set of pathogenic yeasts even at very high drug concentrations of $150 \mu \mathrm{g} / \mathrm{mL}$. 


\subsection{Anti-Biofilm Activity}

Only moderate activities against planktonic cells has also been described for a set of derivatives a snail derived natural antimicrobial peptide, which turned out to possess remarkable capabilities to inhibit the biofilm formation of $C$. auris probably based on a yet so far uncharacterized additional activity at very low concentrations of the peptides [37].

The inhibiting activity of classical antimicrobial peptides is directed (and usually characterized) against free-floating planktonic cells. However, probably the more important microbial lifestyle in fact can be considered to be the biofilm, especially in the case of pathogenic microbes during their interaction with host tissues deciding their success to establish their full pathogenic potential in the onset of an infection $[4,6,26,41,42]$. Although the importance of anti-biofilm drugs has already been recognized in the early times of biofilm research dedicated compounds against Candida species or any other microbe have been and are still awaiting their discovery keeping treatment of biofilm-based infections particularly problematic [26].

The activity against planktonic cells was at most moderate, however, when Pom- 1 and Pom-2 were tested in an experimental setup in which cells were allowed to form biofilms on the polystyrene surface of microtiter plates in the presence of increasing concentrations of the peptides both showed the desired antibiofilm activity. The development of biofilms was drastically reduced for all Candida species. The peptide Pom- 1 showed a slight preference towards C. albicans and C. parapsilosis leading to a reduction of biofilm mass to $12 \%$ and $7 \%$ already at concentrations of $10 \mu \mathrm{g} / \mathrm{mL}$ whereas the susceptibility of $C$. auris diminished resulting in a biofilm reduction to only $28 \%$ for this concentration. Interestingly, in contrary, in the viability assay Pom-1 performed best against $C$. auris planktonic cells. This finding is a remarkable parallel to derivatives of a peptide from the coastal mollusk Cenchritis muricatus which also failed as antimicrobial peptides against $C$. auris planktonic cells but efficiently could inhibit biofilm formation [37]. Nevertheless, the respective semi-inhibitory concentration for biofilm inhibition ( $\mathrm{IC}_{50}$ Biofilm) of Pom-1 were $4.2 \mu \mathrm{g} / \mathrm{mL}$ for C. auris, $4.6 \mu \mathrm{g} / \mathrm{mL}$ for C. albicans and $3.1 \mu \mathrm{g} / \mathrm{mL}$ for C. parapsilosis (Figure 3a). The second peptide Pom-2 also inhibited biofilm formation of all Candida sp. with $\mathrm{IC}_{50 \mathrm{~B}}$ of 2.2, 1.9, $1.5 \mu \mathrm{g} / \mathrm{mL}$ for C. auris, C. albicans and C. parapsilosis, but unlike Pom-1 it lacked the difference between the efficiencies against individual species and was fully active also against $C$ auris with reductions of the final biofilm masses down to $16 \%$ for C. auris, $15 \%$ for C. albicans and $10 \%$ for C. parapsilosis at peptide concentrations of $10 \mu \mathrm{g} / \mathrm{mL}$ (Figure 3b). Both, Pom-1 and Pom-2 appear to be more active in inhibiting biofilm formation than in reducing the viability of planktonic cells which became manifest in the comparison of the respective $\mathrm{IC}_{50}$ values for both processes. Consistently the activities against biofilms were elevated for all Candida species with a minimum of a 2 -fold higher Pom- 1 activity against $C$. auris biofilms up to a 12-fold increase for Pom-2 against $C$. parapsilosis (Figure 3c).

The inhibitory effects of both peptides, Pom- 1 and Pom-2, on early-stage biofilms were unexpectedly pronounced and positive especially with respect to their extremely limited activity towards planktonic cells. The molecular mode of action needs to be further elucidated for Pom-1 and Pom-2 to define to which already known models of pore formation [31] they belong. Nevertheless, one possible explanation for the observed biofilm preference or potentially existing specialized activity on biofilm cells may arise from the socalled charged lipid clustering. In this model of helical peptides accumulate at the surface of membranes and induce clustering of anionic lipids resulting in membrane depolarization and the slow leakage of intracellular content [31,43]. As a side effect of this peptide accumulation on cell surfaces and the alterations in charge distribution drastic effects on the physico-chemical properties of the cell surface with consequences for early events in biofilm formation like cell aggregation, their attachment to the substratum and their growth into microcolonies must be expected. This would probably allow developing optimized peptides with pronounced anti-biofilm properties as lead structures for a potentially new class of specific anti-biofilm drugs. An interesting study in this context identified a peptide from the South American rattlesnake Crotalus durissus terrificus which combined activities 
against planktonic cells of Candida albicans and the respective biofilms [44]. The findings presented here and their possible explanations may in fact qualify Pom-1 and Pom-2 as interesting molecules with a potential novel mode of action and specificity towards biofilms and thus as valuable targets for future in-depth studies to elucidate their properties and working mechanism. Interesting key questions are, then, how the sequence and the resulting structure of the peptides influence their distinct different activities towards planktonic cells and biofilms which can be addressed by repetitive synthesis of sequence variants, subsequent activity testing in combination with biophysical measurements of their interactions with bio-membranes and the consequences of these interactions for membrane (and thus cell) integrity.
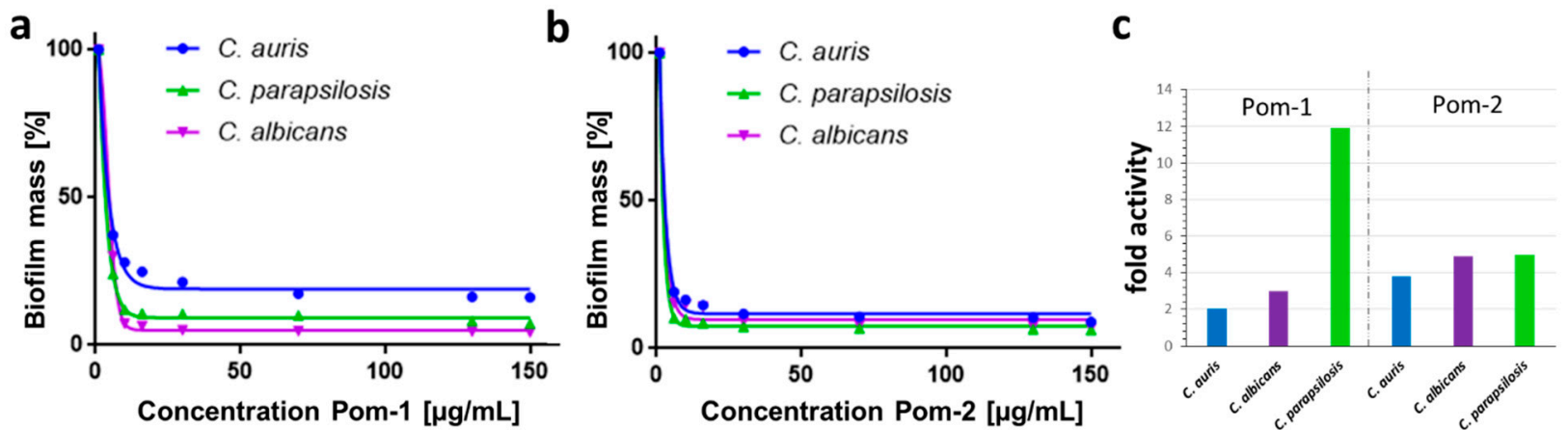

Figure 3. Biofilm inhibition by the peptides Pom-1 and Pom-2 (a,b) dose-dependent inhibition of C. auris, C. parapsilosis and C. albicans de novo biofilm formation by Pom-1 and Pom-2 quantified with crystal violet after $24 \mathrm{~h}$ in triplicates. All experiments were performed in triplicates. Standard deviations have been calculated and found to be too low to be visible in the graphs. Inhibitors were present throughout the growth. (c) Demonstration of the higher activity in biofilm inhibition of Pom-1 and Pom-2 by comparing the ratio of the $\mathrm{IC}_{50 \mathrm{~b}}$ and $\mathrm{IC}_{50 \mathrm{p}}$ values on the Candida species.

\section{Conclusions}

The antimicrobial peptides Pom- 1 and Pom-2 from the Cuban freshwater snail Pomacea poeyana (Pilsbry, 1927) have been shown to moderately reduce viability of C. auris, C. albicans and $C$. parapsilosis cells. Despite these limited activities against planktonic cells both peptides were potent inhibitors of biofilm formation with $\mathrm{IC}_{50}$ values between $1.5-4.6 \mu \mathrm{g} / \mathrm{mL}$. This may qualify the peptides as lead structures for the first biofilm specific fungicide in the future.

\section{Materials and Methods}

\subsection{Cultivation of Candida Species}

Candida auris was purchased from DSMZ (DSMZ-No. 21092), C. albicans (ATCC 90028) and C. parapsilosis (ATCC 22019) were obtained from the Laboratory of Medical Mycology, IPK. The Candida species grown on YPD Agar ( $1 \% w / v$ yeast extract, $2 \% w / v$ peptone, $2 \% w / v$ glucose, $1.5 \%$ Agar). For suspension cultures $10 \mathrm{~mL}$ YPD medium in a $100 \mathrm{~mL}$ Erlenmayer flask was inoculated with a single colony and grown at $37^{\circ} \mathrm{C}$ and orbital shaking at $150 \mathrm{rpm}$. Agar plates containing glucose $(40 \mathrm{~g} / \mathrm{L})$, peptone $(10 \mathrm{~g} / \mathrm{L})$ and agar $(15 \mathrm{~g} / \mathrm{L})$ and were adjusted to a $\mathrm{pH}$ of 5.6 .

\subsection{Peptide Synthesis}

Peptides were Produced by Solid Phase Synthesis as described in Gonzalez Garcia et al., 2020 [38].

\subsection{Viability Tests and Quantification}

For Candida species, the minimal inhibitory concentration (MIC) of Pomacea 1 and 2 and the viability of the yeasts was determined according to the "Clinical and Laboratory Standards Institute" guidelines M27-A3 broth microdilution assay. In brief, $2.5 \times 10^{3}$ yeast cells were seeded in $200 \mu \mathrm{L}$ RPMI-1640 medium supplemented with L-glutamine in a 
flat bottomed, 96-well polystyrene microtiter plates (Sarstedt AG \& Co. KG, Nümbrecht, Germany) and incubated at $37^{\circ} \mathrm{C}$ with agitation at $900 \mathrm{rpm}$ on an Eppendorf shaker. The effect of the different Pomacea derivatives Pom-1 and Pom-2 on the cell viability was tested in the presence of the peptides at different concentrations. The cell viability was quantified by a resazurin assay according to Patricia Bi Fai et al. [39]. The cells were incubated with $100 \mu \mathrm{L}$ resazurin with a concentration of $12 \mu \mathrm{g} / \mathrm{mL}$ for $40 \mathrm{~min}$. Viable cells reduces resazurin to the fluorescent resorufin by the production of NADPH. The amount of produced resorufrin was analyzed by fluorescence measurements at excitation wavelength of 535 and an emission of $595 \mathrm{~nm}$ with a Tecan infinite M200 microplate reader to quantify the viability. The curve was fitted by a non-linear regression with dose-response nonlinear Hill equation. The semi-inhibitory concentration of the planktonic cell viability $\left(\mathrm{IC}_{50 \mathrm{p}}\right)$ represents the point at which the viability of the cells is reduced to $50 \%$ compared to the untreated control. After the incubation $10 \mu \mathrm{L}$ samples were collected for a plate spot assay. Therefore, a dilution row of each sample was performed in RPMI 1640 medium and $3 \mu \mathrm{L}$ microliters of the dilutions were spotted onto Sabouraud agar plates. The agar plates were incubated for $24 \mathrm{~h}$ at $37^{\circ} \mathrm{C}$. The assay was performed according to the method described in Hilgers et al. [45].

\subsection{Biofilm Formation and Quantification/Anti-Biofilm Treatment}

Biofilms were basically formed and analyzed as described previously [46-48]. In brief, $2.5 \times 10^{3}$ yeast cells were seeded in $200 \mu \mathrm{L}$ RPMI-1640 medium supplemented with L-glutamine in a flat bottomed, 96-well polystyrene microtiter plates (Sarstedt AG \& Co. KG, Nümbrecht, Germany) and incubated at $37^{\circ} \mathrm{C}$ without agitation for $24 \mathrm{~h}$. The effect of the different Pomacea on the biofilm formation was tested in the presence of Pom- 1 and Pom-2 at different concentrations. The biofilm was quantified by a crystal violet assay, which was originally developed for bacteria by George $\mathrm{O}^{\prime}$ Toole $[47,49]$ and is also widely used for Candida biofilms $[46,48,50,51]$. Planktonic cells were removed with the supernatant and the mature biofilms were washed twice with $200 \mu \mathrm{L}$ water. Subsequently biofilms were stained with $200 \mu \mathrm{L}$ of a $0.1 \%(w / v)$ crystal violet solution for $15 \mathrm{~min}$. The supernatant was removed, and the biofilms were washed twice with $200 \mu \mathrm{L}$ water to get rid of excess crystal violet. The stained biofilms were air dried for $24 \mathrm{~h}$ at $25^{\circ} \mathrm{C}$ and finally destained using $200 \mu \mathrm{L}$ of $30 \%$ acetic acid $\left(15 \mathrm{~min}, 25^{\circ} \mathrm{C}\right)$. The supernatant was transferred to a fresh 96 well plate and the absorbance at $560 \mathrm{~nm}$ was measured using a Tecan infinite M200 microplate reader to quantify the biofilm biomass. The curve was fitted by a non-linear regression with dose-response nonlinear Hill equation. The semi-inhibitory concentration of biofilm formation $\left(\mathrm{IC}_{50 \mathrm{~b}}\right)$ represents the point at which the biofilm mass is reduced to $50 \%$ compared to the biofilm mass of untreated control.

Author Contributions: Conceptualization, F.R.; methodology, H.F.R., J.S., M.G.-G., F.E.M.V., A.A., A.A.V., D.K., A.W. and J.P.E.; investigation, H.F.R., J.S., M.G.-G., F.E.M.V., J.P.E., A.A., A.-K.K. and A.A.V.; resources, F.R., L.S., A.R. and A.O.-G.; writing-original draft preparation, H.F.R. and F.R.; writing-review and editing, L.S., A.O.-G., F.R., H.F.R.; supervision and project administration, F.R.; funding acquisition, A.W., L.S., A.O.-G., F.R. All authors have read and agreed to the published version of the manuscript.

Funding: This research was funded by the Baden-Württemberg Stiftung in the framework of (NanoMem-To-Tech BioFOM_005), the European Union project "Horizon 2020" (No. 686271) in the framework AD-gut, the German Research Society (DFG) project CRC1279 (Exploiting the Human Peptidome for Novel Antimicrobial and Anticancer Agents), the Alexander von Humboldt-Stiftung, Research Group Linkage Program (No.1160914), Federal Ministry of Education and Research (BMBFWTZ-DLR, GermanyCuba, 2018-2020; BMBF/DLR 01DN18009) and Ministry of Science, Research and the Arts of Baden-Württemberg. Grant Numbers: 7533-10-5-186A, 7533-10-5-186B, 7533-10-5-190.

Institutional Review Board Statement: Not applicable.

Informed Consent Statement: Not applicable.

Data Availability Statement: Not applicable. 
Acknowledgments: The authors thank the Laboratory of Synthetic Peptides, Center for Genetic Engineering and Biotechnology, La Habana, Cuba.

Conflicts of Interest: The authors declare no conflict of interest.

\section{References}

1. Nadell, C.D.; Bassler, B.L.; Levin, S.A. Observing bacteria through the lens of social evolution. J. Biol. 2008, 7, 27. [CrossRef] [PubMed]

2. Licking, E. Getting a grip on bacterial slime. Bloom. Bus. 1999, 3646, 98-100.

3. Davies, D. Understanding biofilm resistance to antibacterial agents. Nat. Rev. Drug Discov. 2003, 2, 114-122. [CrossRef]

4. Fox, E.P.; Nobile, C.J. A sticky situation: Untangling the transcriptional network controlling biofilm development in Candida albicans. Transcription 2012, 3, 315-322. [CrossRef] [PubMed]

5. Fox, E.; Nobile, C. The Role of Candida albicans Biofilms in Human Disease. Candida Albicans Symptoms Causes Treat. Options 2013, 1-24.

6. Hall-Stoodley, L.; Costerton, J.W.; Stoodley, P. Bacterial biofilms: From the natural environment to infectious diseases. Nat. Rev. Microbiol. 2004, 2, 95-108. [CrossRef]

7. Papon, N.; Courdavault, V.; Clastre, M.; Bennett, R.J. Emerging and Emerged Pathogenic Candida Species: Beyond the Candida albicans Paradigm. PLoS Pathog. 2013, 9, e1003550. [CrossRef]

8. Sobel, J.D. Vulvovaginal candidosis. Lancet 2007, 369, 1961-1971. [CrossRef]

9. Paramythiotou, E.; Frantzeskaki, F.; Flevari, A.; Armaganidis, A.; Dimopoulos, G. Invasive fungal infections in the icu: How to approach, how to treat. Molecules 2014, 19, 1085-1119. [CrossRef] [PubMed]

10. Pfaller, M.A.; Diekema, D.J.; Gibbs, D.L.; Newell, V.A.; Ellis, D.; Tullio, V.; Rodloff, A.; Fu, W.; Ling, T.A. Results from the artemis disk global antifungal surveillance study, 1997 to 2007: A 10.5-year analysis of susceptibilities of candida species to fluconazole and voriconazole as determined by CLSI standardized disk diffusion. J. Clin. Microbiol. 2010, 48, 1366-1377. [CrossRef]

11. Tóth, R.; Nosek, J.; Mora-Montes, H.M.; Gabaldon, T.; Bliss, J.M.; Nosanchuk, J.D.; Turner, S.A.; Butler, G.; Vágvölgyi, C.; Gácser, A. Candida parapsilosis: From genes to the bedside. Clin. Microbiol. Rev. 2019, 32, e00111-18. [CrossRef]

12. Harrington, R.; Kindermann, S.L.; Hou, Q.; Taylor, R.J.; Azie, N.; Horn, D.L. Candidemia and invasive candidiasis among hospitalized neonates and pediatric patients. Curr. Med. Res. Opin. 2017, 33, 1803-1812. [CrossRef]

13. Weems, J.J.; Chamberland, M.E.; Ward, J.; Willy, M.; Padhye, A.A.; Solomon, S.L. Candida parapsilosis fungemia associated with parenteral nutrition and contaminated blood pressure transducers. J. Clin. Microbiol. 1987, 25, 1029-1032. [CrossRef]

14. Pammi, M.; Holland, L.; Butler, G.; Gacser, A.; Bliss, J.M. Candida parapsilosis is a significant neonatal pathogen a systematic review and meta-analysis. Pediatr. Infect. Dis. J. 2013, 32, e206-e216. [CrossRef] [PubMed]

15. Pfaller, M.A.; Moet, G.J.; Messer, S.A.; Jones, R.N.; Castanheira, M. Candida bloodstream infections: Comparison of species distributions and antifungal resistance patterns in community-onset and nosocomial isolates in the SENTRY Antimicrobial Surveillance Program, 2008-2009. Antimicrob. Agents Chemother. 2011, 55, 561-566. [CrossRef]

16. Meletiadis, J.; Curfs-Breuker, I.; Meis, J.F.; Mouton, J.W. In vitro antifungal susceptibility testing of Candida isolates with the EUCAST methodology, a new method for ECOFF determination. Antimicrob. Agents Chemother. 2017, 61, e02372-16. [CrossRef] [PubMed]

17. Cantón, E.; Pemán, J.; Quindós, G.; Eraso, E.; Miranda-Zapico, I.; Álvarez, M.; Merino, P.; Campos-Herrero, I.; Marco, F.; De La Pedrosa, E.G.G.; et al. Prospective multicenter study of the epidemiology, molecular identification, and antifungal susceptibility of Candida parapsilosis, Candida orthopsilosis, and Candida metapsilosis isolated from patients with candidemia. Antimicrob. Agents Chemother. 2011, 55, 5590-5596. [CrossRef] [PubMed]

18. Govender, N.P.; Patel, J.; Magobo, R.E.; Naicker, S.; Wadula, J.; Whitelaw, A.; Coovadia, Y.; Kularatne, R.; Govind, C.; Lockhart, S.R.; et al. Emergence of azole-resistant Candida parapsilosis causing bloodstream infection: Results from laboratory-based sentinel surveillance in South Africa. J. Antimicrob. Chemother. 2016, 71, 1994-2004. [CrossRef]

19. Satoh, K.; Makimura, K.; Hasumi, Y.; Nishiyama, Y.; Uchida, K.; Yamaguchi, H. Candida auris sp. nov., a novel ascomycetous yeast isolated from the external ear canal of an inpatient in a Japanese hospital. Microbiol. Immunol. 2009, 53, 41-44. [CrossRef]

20. Morales-López, S.E.; Parra-Giraldo, C.M.; Ceballos-Garzón, A.; Martínez, H.P.; Rodríguez, G.J.; Álvarez-Moreno, C.A.; Rodríguez, J.Y. Invasive infections with multidrug-resistant yeast Candida auris, Colombia. Emerg. Infect. Dis. 2017, 23, 162-164. [CrossRef]

21. Lockhart, S.R.; Etienne, K.A.; Vallabhaneni, S.; Farooqi, J.; Chowdhary, A.; Govender, N.P.; Colombo, A.L.; Calvo, B.; Cuomo, C.A.; Desjardins, C.A.; et al. Simultaneous emergence of multidrug-resistant candida auris on 3 continents confirmed by whole-genome sequencing and epidemiological analyses. Clin. Infect. Dis. 2017, 64, 134-140. [CrossRef]

22. Ben-Ami, R.; Berman, J.; Novikov, A.; Bash, E.; Shachor-Meyouhas, Y.; Zakin, S.; Maor, Y.; Tarabia, J.; Schechner, V.; Adler, A.; et al. Multidrug-resistant candida haemulonii and C. Auris, tel aviv, Israel. Emerg. Infect. Dis. 2017, 23, 195-203. [CrossRef] [PubMed]

23. Osei Sekyere, J. Candida auris: A systematic review and meta-analysis of current updates on an emerging multidrug-resistant pathogen. Microbiologyopen 2018, 7, e00578. [CrossRef]

24. Stone, J. Candida Auris: A New Fungal Superbug Emerging as a Global Threat. Available online: https://www.forbes.com/sites/ judystone/2017/08/24/candida-auris-a-new-fungal-superbug-emerging-as-a-global-threat/?sh=617bf5b53ddd (accessed on 15 November 2020). 
25. Kean, R.; Delaney, C.; Sherry, L.; Borman, A.; Johnson, E.M.; Richardson, M.D.; Rautemaa-Richardson, R.; Williams, C.; Ramage, G. Transcriptome Assembly and Profiling of Candida auris Reveals Novel Insights into Biofilm-Mediated Resistance. $m S p h e r e$ 2018, 3. [CrossRef] [PubMed]

26. Nobile, C.J.; Johnson, A.D. Candida albicans Biofilms and Human Disease. Annu. Rev. Microbiol. 2015, 69, 71-92. [CrossRef]

27. Yang, L.; Harroun, T.A.; Weiss, T.M.; Ding, L.; Huang, H.W. Barrel-stave model or toroidal model? A case study on melittin pores. Biophys. J. 2001, 81, 1475-1485. [CrossRef]

28. Ehrenstein, G.; Lecar, H. Electrically gated ionic channels in lipid bilayers. Q. Rev. Biophys. 1977, 10, 1-34. [CrossRef]

29. Brogden, K.A. Antimicrobial peptides: Pore formers or metabolic inhibitors in bacteria? Nat. Rev. Microbiol. 2005, 3, 238-250. [CrossRef]

30. Hallock, K.J.; Lee, D.K.; Ramamoorthy, A. MSI-78, an analogue of the magainin antimicrobial peptides, disrupts lipid bilayer structure via positive curvature strain. Biophys. J. 2003, 84, 3052-3060. [CrossRef]

31. Nguyen, L.T.; Haney, E.F.; Vogel, H.J. The expanding scope of antimicrobial peptide structures and their modes of action. Trends Biotechnol. 2011, 29, 464-472. [CrossRef]

32. Ciociola, T.; Giovati, L.; Conti, S.; Magliani, W.; Santinoli, C.; Polonelli, L. Natural and synthetic peptides with antifungal activity. Future Med. Chem. 2016, 8, 1413-1433. [CrossRef]

33. Rautenbach, M.; Troskie, A.M.; Vosloo, J.A. Antifungal peptides: To be or not to be membrane active. Biochimie 2016, 130, 132-145. [CrossRef] [PubMed]

34. López-Abarrategui, C.; McBeth, C.; Mandal, S.M.; Sun, Z.J.; Heffron, G.; Alba-Menéndez, A.; Migliolo, L.; Reyes-Acosta, O.; García-Villarino, M.; Nolasco, D.O.; et al. Cm-p5: An antifungal hydrophilic peptide derived from the coastal mollusk Cenchritis muricatus (Gastropoda: Littorinidae). FASEB J. 2015, 29, 3315-3325. [CrossRef] [PubMed]

35. Kubiczek, D.; Flaig, C.; Raber, H.; Dietz, S.; Kissmann, A.K.; Heerde, T.; Bodenberger, N.; Wittgens, A.; González-Garcia, M.; Kang, F.; et al. A Cerberus-Inspired Anti-Infective Multicomponent Gatekeeper Hydrogel against Infections with the Emerging "Superbug" Yeast Candida auris. Macromol. Biosci. 2020, 20. [CrossRef] [PubMed]

36. Vicente, F.E.M.; González-Garcia, M.; Diaz Pico, E.; Moreno-Castillo, E.; Garay, H.E.; Rosi, P.E.; Jimenez, A.M.; Campos-Delgado, J.A.; Rivera, D.G.; Chinea, G.; et al. Design of a Helical-Stabilized, Cyclic, and Nontoxic Analogue of the Peptide Cm-p5 with Improved Antifungal Activity. ACS Omega 2019, 4, 19081-19095. [CrossRef] [PubMed]

37. Kubiczek, D.; Raber, H.; Gonzalez-García, M.; Morales-Vicente, F.; Staendker, L.; Otero-Gonzalez, A.J.; Rosenau, F. Derivates of the antifungal peptide CM-p5 inhibit development of candida auris biofilms in vitro. Antibiotics 2020, 9, 363. [CrossRef]

38. García, M.G.; Rodríguez, A.; Alba, A.; Vázquez, A.A.; Vicente, F.E.M.; Pérez-Erviti, J.; Spellerberg, B.; Stenger, S.; Grieshober, M.; Conzelmann, C.; et al. New antibacterial peptides from the freshwater mollusk Pomacea poeyana (Pilsbry, 1927). Biomolecules 2020, 10, 1473. [CrossRef]

39. Fai, P.B.; Grant, A. A rapid resazurin bioassay for assessing the toxicity of fungicides. Chemosphere 2009, 74, 1165-1170. [CrossRef]

40. Clinical and Laboratory Standards Institute. Reference Method for Broth Dilution Antifungal Susceptibility Testing of Filamentous Fungi-M38-A2; Clinical and Laboratory Standards Institute: Annapolis Junction, MD, USA, 2008; Volume 28, ISBN 1-56238-668-9.

41. Kolter, R.; Greenberg, E.P. Microbial sciences: The superficial life of microbes. Nature 2006, 441, 300-302. [CrossRef] [PubMed]

42. Davey, M.E.; O'toole, G.A. Microbial Biofilms: From Ecology to Molecular Genetics. Microbiol. Mol. Biol. Rev. 2000, 64, 847-867. [CrossRef] [PubMed]

43. Epand, R.M.; Epand, R.F. Bacterial membrane lipids in the action of antimicrobial agents. J. Pept. Sci. 2011, 17, 298-305. [CrossRef] [PubMed]

44. de Aguiar, F.L.L.; Santos, N.C.; de Paula Cavalcante, C.S.; Andreu, D.; Baptista, G.R.; Gonçalves, S. Antibiofilm Activity on Candida albicans and Mechanism of Action on Biomembrane Models of the Antimicrobial Peptide Ctn[15-34]. Int. J. Mol. Sci. 2020, 21, 8339. [CrossRef] [PubMed]

45. Hilgers, F.; Bitzenhofer, N.L.; Ackermann, Y.; Burmeister, A.; Grünberger, A.; Jaeger, K.E.; Drepper, T. Genetically encoded photosensitizers as light-triggered antimicrobial agents. Int. J. Mol. Sci. 2019, 20, 4608. [CrossRef] [PubMed]

46. Jose, A.; Coco, B.J.; Milligan, S.; Young, B.; Lappin, D.F.; Bagg, J.; Murray, C.; Ramage, G. Reducing the incidence of denture stomatitis: Are denture cleansers sufficient? J. Prosthodont. 2010, 19, 252-257. [CrossRef] [PubMed]

47. O'Toole, G.A. Microtiter dish Biofilm formation assay. J. Vis. Exp. 2010, 2437. [CrossRef] [PubMed]

48. Sherry, L.; Ramage, G.; Kean, R.; Borman, A.; Johnson, E.M.; Richardson, M.D.; Rautemaa-Richardson, R. Biofilm-forming capability of highly virulent, multidrug-resistant Candida auris. Emerg. Infect. Dis. 2017, 23, 328-331. [CrossRef] [PubMed]

49. O'Toole, G.; Kaplan, H.B.; Kolter, R. Biofilm formation as microbial development. Annu. Rev. Microbiol. 2000, 54, 49-79. [CrossRef]

50. Negri, M.; Gonçalves, V.; Silva, S.; Henriques, M.; Azeredo, J.; Oliveira, R. Crystal violet staining to quantity Candida adhesion to epithelial cells. Br. J. Biomed. Sci. 2010, 67, 120-125. [CrossRef]

51. Sherry, L.; Rajendran, R.; Lappin, D.F.; Borghi, E.; Perdoni, F.; Falleni, M.; Tosi, D.; Smith, K.; Williams, C.; Jones, B.; et al. Biofilms formed by Candida albicans bloodstream isolates display phenotypic and transcriptional heterogeneity that are associated with resistance and pathogenicity. BMC Microbiol. 2014, 14, 182. [CrossRef] 